\title{
RETROSPECTIVE ANALYSIS OF TYPES AND PREVALENCE OF MAXILLOFACIAL INJURIES: A CROSS-SECTIONAL COMPUTED TOMOGRAPHIC STUDY
}

\author{
Lalatendu Swain ${ }^{* 1}$, Prabhat Nalini Rautray ${ }^{2}$, Mamata Singh ${ }^{3}$. \\ ${ }^{{ }_{1} 1}$ Associate Professor, Dept of Anatomy, GMC\&H, Balasore, Odisha, India. \\ ${ }^{2}$ Assistant Professor, Dept of Radiodiagnosis, GMC\&H, Balasore, Odisha, India. \\ ${ }^{3}$ Assistant Professor, Dept of Radiodiagnosis , SCB MC\&H, Cuttack, Odisha, India.
}

\section{ABSTRACT}

Background: The incidence and epidemiological causes of maxillofacial trauma and facial fractures varies widely in different regions of the world. To reduce morbidity and mortality, early recognition of severe head trauma and concomitant injuries remains an important part of the initial assessment and treatment plan of severely injured patients.

Purpose of the study: To find out the demographic trends, etiology, pattern of trauma, site and severity of fractures and coexisting injuries in patients presented with maxillofacial injury.

Materials and Methods: The study was conducted on 88 patients during the period from may 2017 to april 2018 on patients presented with facio-maxillary injury at S.C.B Medical College \& Ashwini Hospital, Cuttack, Govt. Medical College \& Hosppital, Balasore, Odisha, India.

Results: In this study maxillofacial injuries are more in compare to female (7.8:1). Majority of the cases are observesd in tha age group 21-30 yr followed by $31-40 \mathrm{yr}$ and no cases in more than $70 \mathrm{yr}$ age group. Most common cause is road traffic accident (82.9\%) followed by assult (6.8\%). Maximum number of patients have fracture of mandible (46.6\%) followed by maxilla (31.8\%). Mandibular fractures occurred most commonly in the parasymphyseal region (35.2\%), followed by body (23.8\%). Fracture of maxilla bone was present commonly at body in $15(53.6 \%)$ cases followed by blow out fracture $(21.5 \%)$. Most of the faciomaxillary trauma patients have associated injuries like head injury (52.3\%) followed by Extremities injury (36.4\%).

Conclusion: Maxillofacial injuries commonly due to road traffic accidents are more frequent in male. The routine use of a head as well as full-body CT scan for all severely injured patients is recommended to ensure that no concomitant injury is overlooked.

KEY WORDS: Maxillofacial Injury, Road Traffic Accident, Three Dimentional CT Scan.

Address for Correspondence: Dr Lalatendu Swain, Flat no - 104, Metro Manorama Complex, Kathagola Street, Mangalabag, Cuttack, Odisha, India-753001 Contact no - 9861142747

E-Mail: lalatenduswain1975@gmail.com

Access this Article online

Quick Response code



DOI: $10.16965 /$ ijar.2018.292

Journal Information

International Journal of Anatomy and Research

ICV for 2016
$\mathbf{9 0 . 3 0}$ $\begin{gathered}\text { ISSN (E) 2321-4287 I ISSN (P) 2321-8967 } \\ \text { https://www.ijmhr.org/ijar.htm } \\ \text { DOI-Prefix: https://dx.doi.org/10.16965/ijar }\end{gathered}$

Article Information

Received: 17 Jun 2018

Peer Review: 18 Jun 2018

Revised: None
Accepted: 31 Jul 2018

Published (O): 05 Sep 2018

Published (P): 05 Sep 2018

\section{INTRODUCTION}

The incidence and epidemiological causes of maxillofacial (MF) trauma and facial fractures varies widely in different regions of the world due to social, economical, cultural consequences, awareness of traffic regulations and alcohol consumption. According to the studies in developed countries assault is the leading 
cause of facial fractures followed mostly by motor vehicle accidents, pedestrian collisions, stumbling, sports and industrial accidents but the leading cause shifts to road traffic accidents in underdeveloped or developing areas of the world followed by assaults and other reasons including warfare $[1,2]$. Diagnosis and management facial injuries are a challenge particularly in the setting of coexisting polytrauma in emergency department.

While they occasionally occur as isolated lesions, they are more commonly associated with other serious injuries [3]. Previous studies demonstrate that the rate of concomitant head injuries in cases of facial fracture is as high as 50- $80 \%$ - depending on the location of the fracture [4]. While intracranial injuries occur most often in cases of fractures of the bones of the upper face and maxilla, they are less frequently associated with lesions of the mandible [4]. Besides involvement of the head, other concomitant injuries include the cervical spine and other body part $[3,5]$. To reduce morbidity and mortality, early recognition of severe head trauma and concomitant injuries remains an important part of the initial assessment and treatment plan of severely injured patients. Understanding the cause, severity, and distribution of facial trauma and the concomitant injuries can help in the optimization of the initial clinical treatment and definition of the right time to involve oral surgeon. In this context, it has recently become more commonly recognized that patients with sustained multiple injuries benefit from an early multidisciplinary management in a specialized trauma center [3]. In the present study, we retrospectively analyzed the patients presented with maxillofacial fractures in terms of demographics, etiology, pattern of MF trauma, site and severity of fractures and coexisting injuries.

\section{MATERIALS AND METHODS}

The study was conducted during the period from may 2017 to april 2018 on patients presented with facio-maxillary injury at S.C.B Medical College \& Ashwini Hospital, Cuttack, Govt. Medical College \& Hosppital, Balasore, Odisha, India. Patients with facio-maxillary fractures were included in the study. The diagnosis of a fracture was based on the history, signs and symptoms, visual finding, manual examination, and maxillofacial CT scan. Exact determination of site and pattern of bony injury was determined by correlating it radiographically using three dimentional CT scan of face.

Our study's variables are presented as; age, gender, cause of injury, site of injury,coexisting intracranial, cervical, orthopedic, abdominal and thoracic injuries. During the analyses Mid-face region injuries were classified as Le Fort I, Le Fort II, Le Fort III, blow out, zygomaticomaxillary complex, nasorbitoethmoid complex and zygomatic arc fractures. If the patient suffered from multiple fractures, each fracture was analyzed separately. Fracture classification was conducted by a radiologist, anatomists neuroradiologist, trauma surgeon and plastic or cranio-maxillo-facial surgeon.

The following parameters were collected and examined retrospectively: gender, age at time of injury, circumstances regarding the mechanism of injury, site of injury,coexisting intracranial, cervical, orthopedic, abdominal and thoracic injuries. During the analyses Mid-face region injuries were classified as Le Fort I, Le Fort II, Le Fort III, blow out, zygomaticomaxillary complex, nasorbitoethmoid complex and zygomatic arc fractures. If the patient suffered from multiple fractures, each fracture was analyzed separately.Concomitant injuries were defined as any major injury outside the facial region and were identified according to body region and severity.

Fig. 1: Fracture of the right ramus \& left condyle of mandible.

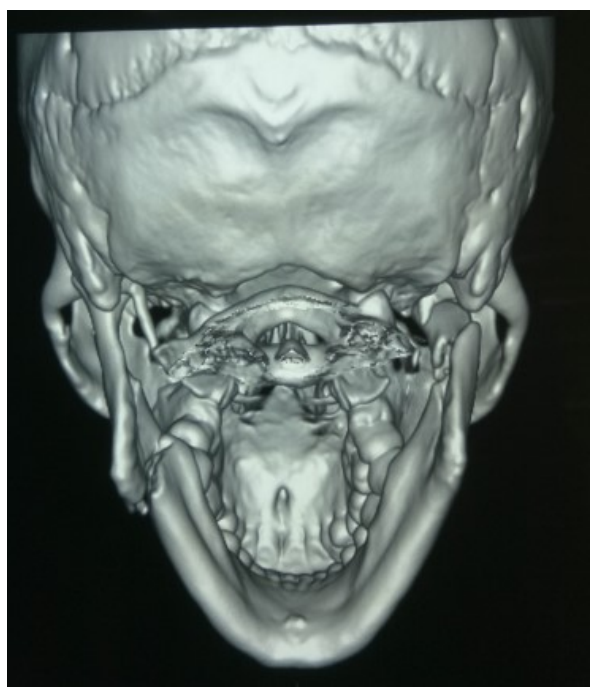


Fig. 2: Fracture of the right ramus of mandible.

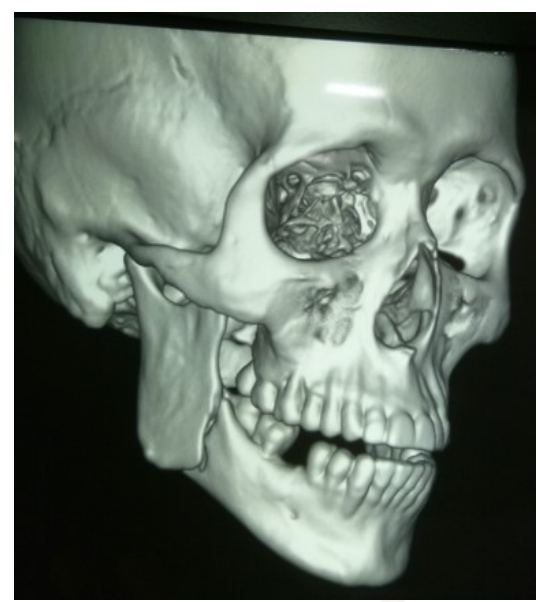

Fig. 3: Fracture anterior and infero lateral wall of right maxillary sinus with collection in right maxillary antrum.



Fig. 4: Fracture of the Right side zygoma bone.

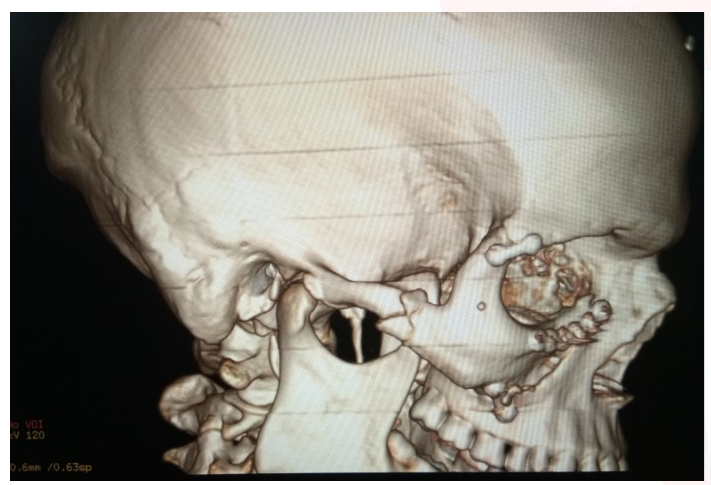

Fig. 5: Fracture frontal bone.

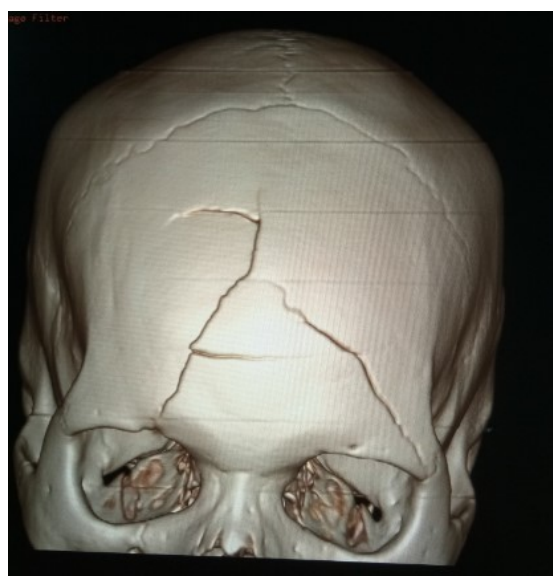

Fig. 6a: Depressed fracture of the frontal bone

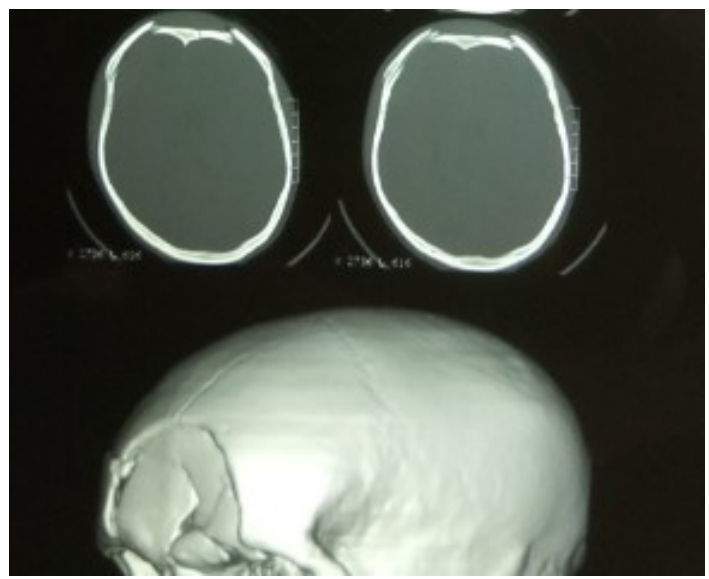

Fig. 6b: Depressed fracture of frontal bone with bilateral frontal contusion and right sided SDH

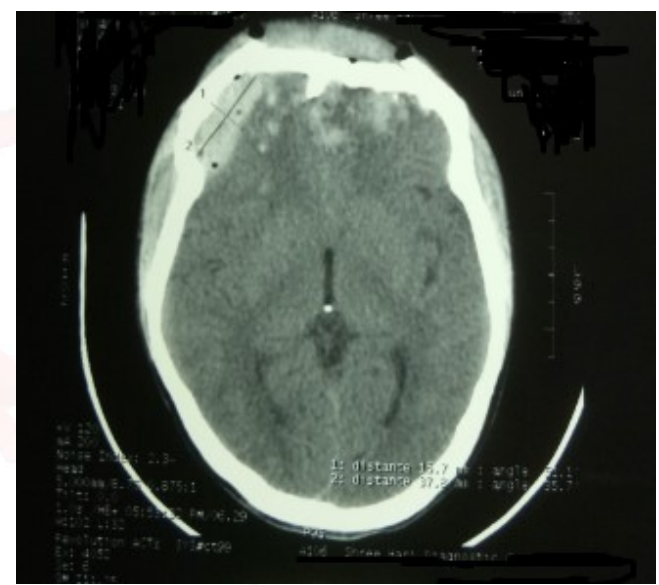

\section{RESULTS}

In this study on 88 cases, 78 are male (88.6\%) and $10(11.4 \%)$ are female. In our study gender wise distribution male : female was 7.8:1. (Graph 1)

Graph 1: Gender wise distribution of cases.

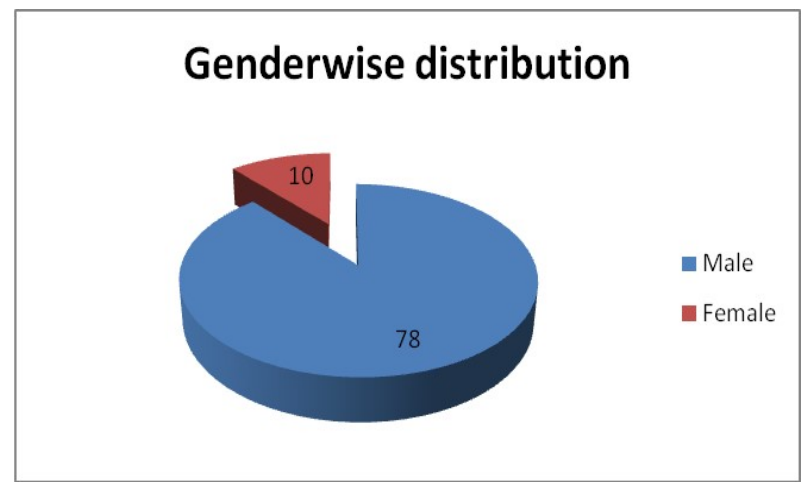

Majority of the cases are observesd in tha age group 21-30 yr in 32 (36.7\%) cases followed by $31-40$ yr in 16 (18.2\%), 11-20 yr in 14 (15.9\%), 41-50 yr in 12 (13.6\%), 51-60yr in 7 (7.9\%), 0-10 yr in 6 (6.8\%), 61-70 yr in 1 (1.1\%) and no cases in more than $70 \mathrm{yr}$ age group. (Table 1) 
Table 1: Age wise distribution of cases.

\begin{tabular}{|c|c|c|}
\hline Age group & $\mathrm{n}=\mathbf{8 8}$ & $\%$ \\
\hline $\mathbf{0 - 1 0}$ & 6 & 6.8 \\
\hline $11-20$ & 14 & 15.9 \\
\hline $\mathbf{2 1 - 3 0}$ & 32 & 36.7 \\
\hline $\mathbf{3 1 - 4 0}$ & 16 & 18.2 \\
\hline $\mathbf{4 1 - 5 0}$ & 12 & 13.6 \\
\hline $\mathbf{5 1 - 6 0}$ & 7 & 7.9 \\
\hline $\mathbf{6 1 - 7 0}$ & 1 & 1.1 \\
\hline $\mathbf{7 1 - 8 0}$ & 0 & 0 \\
\hline $\mathbf{8 1 - 9 0}$ & 0 & 0 \\
\hline
\end{tabular}

Fractures due to RTAs was most common seen in $73(82.9 \%)$ cases, followed by assult in 6 (6.8\%), fall from height in $3(3.4 \%)$ and one case (1.1\%) each due to sports injury, fire arm injury, burns, animal bite, railway accident and occupational related. (Table 2)

Table 2: Distribution of cases according to their etiology.

\begin{tabular}{|l|c|c|}
\hline \multicolumn{1}{|c|}{ Etiology } & $\mathrm{n}=\mathbf{8 8}$ & $\%$ \\
\hline RTA & 73 & 82.9 \\
\hline Fall from height & 3 & 3.4 \\
\hline Assult & 6 & 6.8 \\
\hline Sports & 1 & 1.1 \\
\hline Fire arm injury & 1 & 1.1 \\
\hline Burns & 1 & 1.1 \\
\hline Animal bite & 1 & 1.1 \\
\hline Railway accident & 1 & 1.1 \\
\hline Occupational & 1 & 1.1 \\
\hline
\end{tabular}

Maximum number of patients presented with faciomaxillary injury have fracture of mandible in $41(46.6 \%)$ cases followed by maxilla in 28 (31.8\%), zygomatic complex in 18 (20.4\%), nasal bone in 14 (15.9\%), frontal in $8(9.1 \%)$ and orbital bone in $2(2.3 \%)$ cases. Many patients have combination of fracture sites like Mandible + maxilla in 22 (25.0\%), Mandible + zygoma in 12 (13.6\%), Maxilla + zygoma in 16 (18.2\%), Mandible + maxilla+ zygoma in $13(14.8 \%)$ and Naso orbito ethmoid in 1 (1.1\%) cases. (Tab.3)

Table 3: Distribution of cases according to site of fracture.

\begin{tabular}{|l|c|c|}
\hline \multicolumn{1}{|c|}{ Bones } & $\mathrm{n}=88$ & $\%$ \\
\hline Mandible & 41 & 46.6 \\
\hline Maxilla & 28 & 31.8 \\
\hline Zygomatic complex & 18 & 20.4 \\
\hline Nasal & 14 & 15.9 \\
\hline Frontal & 8 & 9.1 \\
\hline Mandible + maxilla & 22 & 25 \\
\hline Mandible + zygoma & 12 & 13.6 \\
\hline Maxilla + zygoma & 16 & 18.2 \\
\hline Mandible +maxilla+zygoma & 13 & 14.8 \\
\hline Naso orbito ethmoid & 1 & 1.1 \\
\hline Orbit & 2 & 2.3 \\
\hline
\end{tabular}

Mandibular fractures occurred most commonly in the parasymphyseal region in about 31 cases (35.2\%), followed by body in 21 (23.8\%), subcondyle in $16(18.2 \%)$, angle in $13(14.8 \%)$, symphyseal in $4(4.5 \%)$ and one fracture $(1.1 \%)$ each at ramus, condyle, coronoid process and compound fractures in 19 (21.6\%) cases. (Tab.4). Table 4: Distribution of cases according to site of mandibular fracture.

\begin{tabular}{|l|c|c|}
\hline \multicolumn{1}{|c|}{ Site } & $\mathrm{n}=\mathbf{8 8}$ & $\%$ \\
\hline Symphysis & 4 & 4.5 \\
\hline Parasymphysis & 31 & 35.2 \\
\hline Body & 21 & 23.8 \\
\hline Angle & 13 & 14.8 \\
\hline Ramus & 1 & 1.1 \\
\hline Subcondyle & 16 & 18.2 \\
\hline Condyle & 1 & 1.1 \\
\hline Coronoid & 1 & 1.1 \\
\hline Compound & 19 & 21.6 \\
\hline
\end{tabular}

Fracture of maxilla bone was present commonly at body in 15 (53.6\%) cases followed by blow out fracture in $6(21.5 \%)$, Lefort 3 fracture in 4 (21.4\%), Lefort 2 fracture in $2(7.1 \%)$ and Lefort 1 fracture in $1(3.6 \%)$ cases.( Graph 2 )

Graph 2: Distribution of cases according to types of maxilla fracture.



Most of the faciomaxillary trauma patients have associated injuries like head injury in 46 (52.3\%) cases followed by Extremities injury in 32 (36.4\%), Neck injury in 16 (18.2\%), Thoracic injury in 12 (13.6\%), Abdominal injury in 8 (9.1\%) and Pelvic injury in $3(3.4 \%)$ cases. Among the 46 cases with head injury, Intracranial Bleeding was present in maximum cases in 39 (44.3\%) followed by Subdural hemorrhage in 21 (23.9\%), Epidural hemorrhage in 17 (19.3\%), Parenchymal hemorrhage in 16 (18.2\%), pneumocephalus (17.1\%) and Subarachnoidal Hemorrhage in 14 (15.9\%), diffuse axonal injury (5.7\%) cases. (Table 5) 
Table 5: Distribution of cases according to other associated injuries.

\begin{tabular}{|c|l|c|c|}
\hline \multicolumn{2}{|c|}{ Associated injuries } & $\mathrm{n}=\mathbf{8 8}$ & $\%$ \\
\hline \multirow{4}{*}{\begin{tabular}{c} 
Head injury $\begin{array}{c}\mathbf{N}=\mathbf{4 6} \\
\mathbf{5 2 . 3 \% )}\end{array}$ \\
\cline { 2 - 4 }
\end{tabular}} & Intracranial Bleeding & 39 & 44.3 \\
\cline { 2 - 4 } & Epidural hemorrhage & 17 & 19.3 \\
\cline { 2 - 4 } & Subdural hemorrhage & 21 & 23.9 \\
\cline { 2 - 4 } & Pubarachnoidal hemorrhage & 14 & 15.9 \\
\cline { 2 - 4 } & Pneumicephalus & 16 & 18.2 \\
\cline { 2 - 4 } & Diffuse axonal injury & 15 & 17.1 \\
\hline \multicolumn{2}{|c|}{ Neck injury } & 16 & 5.7 \\
\hline \multicolumn{2}{|c|}{ Thoracic injury } & 12 & 18.2 \\
\hline \multicolumn{2}{|c|}{ Abdominal injury } & 8 & 9.1 \\
\hline \multicolumn{2}{|c|}{ Extremities injury } & 32 & 36.4 \\
\hline Pelvic injury & 3 & 3.4 \\
\hline
\end{tabular}

\section{DISCUSSION}

Severely injured patients often exhibit injuries in then maxillofacial region, ranging from small lacerations to multiple and life-threatening fractures of the facial bones. In the literature the incidence of these concomitant facial injuries in multiple injured patients range between 15 and $22 \%[12,13]$. Although many studies have investigated the epidemiology of maxillofacial injures, most of them focus on a single type of concomitant injury like brain or cervical spine [14], have emphasized on concomitant injuries with a particular type of facial fracture [15], or have investigated facial injuries in response to trauma mechanism. Although only few examinations exist, that pertain to the incidence of maxillofacial injuries in a general population of severely injured patients, the data of most of the underlying investigations was collected twenty years ago and safety precautions have since significantly improved. Therefore, the aim of the present study is to give a comprehensive overview of maxillofacial injuries in a general population of severely injured patients at the present time.

We conducted this study on 88 diagnosed case of faciomaxillary fracture. We studied that incidence of faciomaxillary fracture was more in males $(88.6 \%)$ in compare to females (11.4\%). Males sustained significantly more injuries as compared to females, with an overall ratio of 7.8:1. Similarly Vibha Singh et al [6] have also observed faciomaxillary fracture more common in males ( $89.6 \%$ vs $10.3 \%, 9: 1)$. Max J. Scheyerer1 et al [7] also recorded higher fracture rate in males compare to females ( $82 \%$ vs $18 \%$, 5:1). S. E. Udeabor et al [8] also observed more commonly in men (75.6\%) than women (24.4\%), (3:1). Engin D Arslan et al [9] in their study observed male-to-female ratio was 2.8:1. Sunita Malik et al [10] also observed faciomaxillary fractures in favour of males with male female ratio of 2.9:1. Vishal Garg et al [11] studied among faciomaxillary patients percentage of male victims (85.4\%) was more than the females $(14.6 \%)$, in the ratio of $6: 1$.

In this study we observed that majority of the cases were in tha age group $21-30$ yr (36.7\%) followed by $31-40 \mathrm{yr}(18.2 \%), 11-20 \mathrm{yr}(15.9 \%)$, $41-50$ yr (13.6\%), 51-60yr (7.9\%), 0-10 yr (6.8\%), $61-70 \mathrm{yr}(1.1 \%)$ and no cases in more than $70 \mathrm{yr}$ age group. Similarly Vibha Singh et al [6] studied maximum number of subjects in the age group 21-30 yr (37.6\%) followed by 31- 40 (19.3\%). In accordance to us Max J. Scheyerer1 et al [7] found that most of the cases were in age ranged from 16 to 91 years with a mean age of 44. S. E. Udeabor et al [8] observed that those in the third and fourth decades of life mostly affected (46.5\% and $22.1 \%$, resp.). Engin D Arslan et al [9] concluded that majority of the patients (57.4\%) were between the age of 18-39 year. Sunita Malik et al [10] found most of the patient were between 18 and 34 years old. Vishal Garg et al [11] studied among faciomaxillary patients the commonest age group involved was between $16-30$ years (44.6\%) followed by $31-45$ years ( $37.7 \%$ ).

In our study we observed most common cause of maxillofacial fractures was road traffic accidents seen in $82.9 \%$ of cases, followed by assult in $6.8 \%$, fall from height in $3.4 \%$ and $1.1 \%$ of cases each due to sports injury, fire arm injury, burns, animal bite, railway accident and occupational related. In accordance to us Vibha Singh et al [6] also found road traffic accident $(97.10 \%)$ as the most common etiological factor followed by fall from height in $2.11 \%$, assult in $0.38 \%$, fire arm injury in $0.11 \%$ and animal bite in $0.11 \%$ of cases. Similarly S. E. Udeabor et al [8] in their study seen road traffic accident (RTA) was the commonest cause of maxillofacial fractures accounting for $46.5 \%$; assault was second (19.8\%), whereas animal attack was the least among the causes (1.2\%). 
Similar to us Sunita Malik et al [10] found the most common causes of maxillofacial injuries was traffic accidents involving $72.7 \%$ of cases followed by assault involving $11.6 \%$ and injury associated with fall involving $8 \%$; the remaining injuries were due to variety of causes including occupational (3\%), sports (2\%) and miscellaneous ( $<3 \%)$. In contrast to us Max J. Scheyerer1 et al [7] observed fall from height as the most common cause seen in $37 \%$ cases followed by motor vehicle collisions in $21 \%$, bicycle accidents in $19 \%$ and other causes were pedestrian-car-accidents and assaults. Engin D Arslan et al [9] studied the most common cause of injuries were violence, accounting for $39.7 \%$ of the sample, followed by falls $27.9 \%$ and road traffic accidents $27.2 \%$. In patients between 20 to 49 years violence was the main cause of injuries, whereas after 50 years old falls were the primary cause of injuries. Vishal Garg et al [11] studied the most common cause of facial trauma was road traffic accident (83.1\%) followed by assault (7.7\%), fall from height (3.8\%), electric burns (3.1\%), burns (1.5\%) and railway accident $(0.8 \%)$.

In this study we observed maximum number of patients presented with faciomaxillary injury have fracture of mandible $(46.6 \%)$ followed by maxilla (31.8\%), zygomatic complex (20.4\%), nasal bone (15.9\%), frontal (9.1\%) and orbital bone $(2.3 \%)$ cases. Many patients have combination of fracture sites like Mandible + maxilla (25.0\%), Mandible + zygoma (13.6\%), Maxilla + zygoma (18.2\%), Mandible + maxilla+ zygoma $(14.8 \%)$ and Naso orbito ethmoid (1.1\%) cases. Similarly Vibha Singh et al [6] concluded that most common fracture in faciomaxillary injury patients was mandibular fracture $(47.8 \%)$ followed by maxilla (26.4\%), zygomatic complex (21.6\%), naso orbito ethmoid $(0.96 \%)$ and orbital bone $(0.48 \%)$ cases the common type of combination fractures they observed was Mandible + maxilla+ zygoma (62.4\%). Sunita Malik et al [10] also observed mandible was commonly involved in $71.27 \%$ patients followed by zygomaticomaxillary complex (11.60\%), nasal in $(7.18 \%)$, maxilla in (7.18\%) and orbital fractures $(2.76 \%)$. S. E. Udeabor et al [8] also found mandibular fractures (59.3\%)were the most frequently fractured bone of the maxillofacial skeleton, followed by zygomatic complex fractures (18.5\%) and maxillary fractures (14.1\%), naso orbito ethmoid (3\%) and orbital bone (2.9\%), frontal (1.5\%), nasal bone $(0.7 \%)$ of cases. According to Max J. Scheyerer1 et al [7] study, most common overall facial bone fracture was orbital (78\%), followed by maxillary (70 \%) and zygomatic (55 $\%)$ fractures. The most common isolated fracture was of the mandible (6\%). Lefort fractures were found in $24 \%$ of cases of maxillary fractures. In contrast to our study Engin D Arslan et al [9] seen most frequent fracture was of maxillary bone $(28,0 \%)$ followed by nasal bone $(25,3 \%)$, zygoma $(20,2 \%)$, the mandible $(\% 8,4)$ frontal bone $(8,1 \%)$ and nasoethmoidoorbital bone $(\% 3,1)$. In contrast to us Vishal Garg et al [11] observed equal incidence of fracture of nasal bone \& mandible (18.5\%) followd by maxilla (8.5\%), zygomatic (3.1\%) and orbit $(2.3 \%)$ cases,

We observed most common site of mandibular fractures was parasymphyseal region seen in (35.2\%), followed by body in (23.8\%), subcondyle in $(18.2 \%)$, angle in (14.8\%), symphyseal in (4.5\%) and one fracture (1.1\%) each at ramus, condyle, coronoid process and compound fractures in $21.6 \%$ cases. Similar to us Sunita Malik et al [10] found the most prominent site of mandibular fracture was parasymphysis (21.70\%) followed by angle (16.27\%), body (13.95\%), symphysis (9.30\%), condyle (6.20\%), ramus $(3.9 \%)$ and coronoid (1.5\%), and combination fractures involving more than one site were present in $27.13 \%$ of cases. While Vibha Singh et al [6] studied the most common site of mandibular fracture was body (51.5\%) followed by parasymphysis $(45.2 \%)$, condyle \& subcondyle $(27.1 \%)$, angle $(26.9 \%)$, symphysis $(4.2 \%)$, ramus $(1.6 \%)$ and coronoid process (1.08\%). S. E. Udeabor et al [8] observed in the mandible, the body (23.7\%) had the highest number of fractures followed by parasymphysis (14.1\%), angle (9.6\%), dento-alveolar (4.4\%), condylar (3.7\%), symphysis (2.2\%) and ramus (1.5\%). Engin D Arslan et al [9] studied the main fracture site in cases with mandibular fractures was mandibular corpus $(28,5 \%)$ followed by ramus $(23,8 \%)$, compound $(26.9 \%)$, condyle $(22.2 \%)$, parasymphysis $(6.3 \%)$ and symphysis (3.17\%). 
In this study we observed presence of fracture of maxilla bone commonly at body $(53.6 \%)$ cases followed by blow out fracture (21.5\%), Lefort 3 fracture $(21.4 \%)$, Lefort 2 fracture $(7.1 \%)$ and Lefort 1 fracture (3.6\%). Similar to us Engin D Arslan et al [9] observed fracture of maxilla bone most commonly at body (64.4\%) cases followed by blow out fracture in $21.8 \%$, Lefort 3 fracture in $9 \%$, Lefort 2 fracture in $3.7 \%$ and Lefort 1 fracture in $0.9 \%$ cases. In contrast Vibha Singh et al [6] shown, among maxillary fractures, the most common fracture was leforte 2 fracture $(84.00 \%)$ followed by leforte 1 and then leforte 3. While Max J. Scheyerer1 et al [7] found Lefort 3 fracture in 13\%, Lefort 1 fracture in $9 \%$ and Lefort 2 fracture in 2\%). S. E. Udeabor et al [8] studied Lefort 1 fracture in 9\%, Lefort 2 fracture in $2 \%$ and Lefort 3 fracture in $13 \%$ cases. Sunita Malik et al [10] detected Lefort 1 fracture as the common type of maxilla fracture followed by Lefort 2 and Lefort 3 fracture.

In our study we found most of the faciomaxillary trauma patients have associated injuries like head injury $(52.3 \%)$ cases followed by extremities injury (36.4\%), neck injury in 16 (18.2\%), thoracic injury in (13.6\%), abdominal injury (9.1\%) and Pelvic injury (3.4\%) cases. Among the 46 cases with head injury, intracranial bleeding was present in maximum cases (44.3\%) followed by subdural hemorrhage (23.9\%), epidural hemorrhage (19.3\%), parenchymal hemorrhage (18.2\%), pneumocephalus (17.1\%) and subarachnoidal hemorrhage (15.9\%), diffuse axonal injury $(5.7 \%)$ cases. In accordance with us Max J. Scheyerer1 et al [7] observed most of the faciomaxillary trauma patients have associated injuries like head injury including intracranial bleeding (72\%), subdural hemorrhage (36\%), epidural hemorrhage (19.3\%), parenchymal hemorrhage (19\%), and subarac-hnoidal hemorrhage $(18 \%)$ cases followed by extremities injury (58\%), chest injury (49\%), spine (23\%), abdominal injury $(19 \%)$ and neck injury (18\%) cases. Similarly Sunita Malik et al [10] studied faciomaxillary trauma patients have associated injuries most commonly at head \& neck region (50.2\%) followed by extremities (27.2\%), thoracic (11.2\%), abdominal (8.8\%) and Pelvis (2.3\%) cases. Engin D Arslan et al [9] observed injuries to upper extremity, lower extremity, chest, pelvis and abdomen were in 5,8\%, 4,6\%, $4 \%, 1,9 \%$ and $1,6 \%$ of patients respectively. They also observed subarachnoid hemorrhage (44.1\%), brain contusion (22\%), epidural hemorrhage (20.5\%), pneumocephalus (19.1\%), subdural hemorrhage (16.1\%) and diffuse axonal injury (5.8\%) cases. In contrast to us Vishal Garg et al [11] observed maxillofacial injury commonly associated with extremities injury (30.0\%) followed by head injury ( $21.5 \%)$, thoracic injury $(10.8 \%)$, neck injury (3.8\%) and abdominal injury $(0.8 \%)$ cases.

\section{CONCLUSION}

The results of this study exhibit that road traffic accidents is the main reason for maxillofacial injuries followed by fall from height. Maxillofacial injuries are more frequent in male than in female. The mandible was most frequently involved facial bone. The association of high number of accompanying intracranial lesions emphasizes the need to screen all trauma patients (with facial fracture) for brain injuries, irrespective of obvious signs and symptoms. Therefore, the routine use of a head as well as full-body CT scan for all severely injured patients is recommended to ensure that no concomitant injury is overlooked.

\section{ABBREVIATION}

MF - Maxillofacial

RTA - Road traffic accident

CT-Computed tomography

Conflicts of Interests: None

\section{REFERENCES}

[1]. Lee JH, Cho BK, Park WJ: A 4-year retrospective study of facial fractures on Jeju, Korea. J Craniomaxillofac Surg 2010;38(3):192-196.

[2]. Mohajerani SH, Asghari S: Pattern of mid-facial fractures in Tehran, Iran. Dent Traumatol 2011;27(2):131-134.

[3]. Down KE, Boot DA, Gorman DF. Maxillofacial and associated injuries in severely traumatized patients: implications of a regional survey. Int J Oral Maxillofac Surg. 1995;24:409-12.

[4]. Nakhgevany KB, LiBassi M, Esposito B. Facial trauma in motor vehicle accidents: etiological factors. Am J Emerg Med. 1994;12:160-3.

[5]. Alvi A, Doherty T, Lewen G. Facial fractures and concomitant injuries in trauma patients. Laryngoscope. 2003;113:102-6. 
[6]. Vibha Singh, Laxman Malkunje, Shadab Mohammad, Nimisha Singh, Satish Dhasmana, and Sanjib Kumar Das. The maxillofacial injuries: A study. Natl J Maxillofac Surg. 2012 Jul-Dec;3(2):166-171.

[7]. Max J. Scheyerer, Robert Döring, Nina Fuchs, Philipp Metzler, Kai Sprengel, Clement M. L. Werner, HansPeter Simmen, Klaus Grätz and Guido A. Wanner. Maxillofacial injuries in severely injured patients. Journal of Trauma Management \& Outcomes 2015;9:4

[8]. S. E. Udeabor, B. O. Akinbami, K. S. Yarhere, and A. E. Obiechina. Maxillofacial Fractures: Etiology, Pattern of Presentation, and Treatment in University of Port Harcourt Teaching Hospital, Port Harcourt, Nigeria. Hindawi Publishing Corporation Journal of Dental Surgery Volume 2014, Article ID 850814, 5 page.

[9]. Engin D Arslan, Alper G Solakoglu, Erdal Komut, Cemil Kavalci, Fevzi Yilmaz, Evvah Karakilic, Tamer Durdu and Muge Sonmez. Assessment of maxillofacial trauma in emergency Department. World Journal of Emergency Surgery 2014, 9:13.

[10]. Sunita Malik, Gurdarshan Singh, Gagandeep Kaur, Sunil Yadav, Hitesh C. Mittal Orofacial trauma in rural India: A clinical study. Chinese Journal of Traumatology 2017;20:216e221.
[11]. Vishal Garg, Harinder Singh, K Vij. Trends of Maxillofacial Trauma at Tertiary Care Hospital in Rural Area of Southern Punjab. J Indian Acad Forensic Med. Jan- March 2012;34(1).

[12]. Down KE, Boot DA, Gorman DF. Maxillofacial and associated injuries in severely traumatized patients: implications of a regional survey. Int J Oral Maxillofac Surg. 1995;24:409-12.

[13]. Cannell H, Paterson A, Loukota R. Maxillofacial injuries in multiply injured patients. $\mathrm{Br} J$ Oral Maxillofac Surg. 1996;34:303-8.

[14]. Elahi MM, Brar MS, Ahmed N, et al. Cervical spine injury in association with craniomaxillofacial fractures. Plast Reconstr Surg. 2008;121:201-8.

[15]. Follmar KE, Debruijn M, Baccarani A, et al. Concomitant injuries in patients with panfacial fractures. J Trauma. 2007;63:831-5.

How to cite this article:

Lalatendu Swain, Prabhat Nalini Rautray, Mamata Singh. RETROSPECTIVE ANALYSIS OF TYPES AND PREVALENCE OF MAXILLOFACIAL INJURIES: A CROSS-SECTIONAL COMPUTED TOMOGRAPHIC STUDY. Int J Anat Res 2018;6(3.3):5613-5620. DOI: 10.16965/ijar.2018.292 